\title{
Impact of PPIs on patient focused symptomatology in GERD
}

\author{
ABR Thomson \\ Division of Internal Medicine, \\ Department of Medicine, University \\ of Alberta, Edmonton, Alberta, Canada
}

\begin{abstract}
About half of patients with gastroesophageal reflux disease (GERD) have a normal endoscopy, so symptom assessment is the only appropriate outcome measure for these persons. Symptom assessment is also of great importance in persons with erosive esophagitis. There is currently no fully validated questionnaire to compare symptom response to treatment of patients with GERD. The aim of this review is to consider ReQuest ${ }^{\mathrm{TM}}$ assessment tool to evaluate esophageal, supra-esophageal, and infra-esophageal symptoms, as well as any modification of the patient's quality of life. The ReQuest ${ }^{\mathrm{TM}}$ may be combined with the Los Angeles classification of esophagitis (LA A-D), to include the normal endoscopic finding in normal endoscopy reflux disease. The ReQuest ${ }^{\mathrm{TM}}$ score declines rapidly towards normal with patient treatment with a proton pump inhibitor. A proportion of patients need more than the usual 8 weeks of therapy. For example, in GERD patients with Los Angeles B-D, the ReQuest ${ }^{\mathrm{TM}}$ score falls more with pantoprazole $40 \mathrm{mg}$ than with esomoprazole $40 \mathrm{mg}$ after 12 weeks of therapy. Now that the simplified ReQuest in Practice ${ }^{\mathrm{TM}}$ is available, this validated brief questionnaire has potential as an instrument for use in GERD patients seen in everyday clinical practice.
\end{abstract}

Keywords: complete healing, dyspepsia, erosive esophagitis, GERD symptoms, pH, ReQuest ${ }^{\mathrm{TM}}$

\section{Introduction}

In a review of the impact of proton pump inhibitors (PPIs) on the symptomatology of gastroesophageal reflux disease (GERD) symptoms, one would not expect the need to return first to basics to refine a definition of terms. But, that is exactly what is needed in order to be more precise in considering just what it is that we mean by the symptomatology of GERD. The major challenge in the assessment of the effect of PPIs on GERD symptoms is to use the appropriate measurement tool. This tool must account for all GERD-related symptoms as well as Quality of Life (Q of L) issues, it must be reproducible, and be sensitive enough to measure therapy-associated changes.

The ReQuest ${ }^{\mathrm{TM}}$ scale has become increasingly used in clinical trials for the purpose of demonstrating possible superiority in symptom relief between PPIs. However, this ReQuest $^{\mathrm{TM}}$ assessment tool assessment tool is also useful to demonstrate the high efficiency of all PPIs in the amelioration of GERD symptoms in clinical practice (Rubin et al 2008). Additional concepts that have developed from this research program include complete healing, ie, complete resolution of GERD-associated symptoms as well as the healing of any associated erosive esophagitis (EE). A further concept is that the acute course of therapy may need to be extended from the usual 4-8 weeks (chosen to achieve higher rates of healing of EE) to 12 weeks in order to obtain not just healing of EE, but equally importantly to resolve all GERD symptoms.

It has been reported that about $44 \%$ of the US population have GERD-related symptoms once a month, and 20\% once a week (Nebel et al 1976; Gallup 1988; Locke et al 1997; Fass et al 2001). GERD affects 10\%-30\% of otherwise healthy persons 
in other Western countries (Stanghellini et al 2004), and the economic impact of treating these persons is enormous. To sufferers of GERD, these unfortunate persons are only too aware of the plethora of symptoms, be these related to acid, other upper gastrointestinal (GI) symptoms, supra(extra-) esophageal complaints, those related to the lower GI tract, or to impaired quality of life (Q of L) from issues such as loss of nighttime sleep. Persons with GERD have significantly $(\mathrm{p}<0.05)$ poorer health related quality of life than do the general population (Pare et al 2003), patients with diabetes or hypertension (Enck et al 1999), or patients with severe angina pectoris or mild cognitive heart failure (Dimenas et al 1993). Improvement of the Q of L in GERD is proportional to the frequency and sensitivity of esophageal or non-esophageal symptoms, irrespective of findings on esophagogastroduodenoscopy (EGD) (Dimenas et al 1996; Dent et al 1999; Kaplan-Machlis et al 1999; Malfertheiner et al 2006).

Although there are over 1000 clinical studies of the use of the various proton pump inhibitors (PPIs) available worldwide, it is only in the past 5 years that the primary outcome response has become the multitude of symptoms arising from GERD, and not just the most common symptoms of heartburn and regurgitation so often the symptom focus in clinical studies of GERD. In retrospect, it is difficult to understand how this had not come about sooner. Indeed, for the longest time the primary outcome assessment in clinical studies was the healing of EE.

Only when community endoscopic studies of the prevalence of conditions associated with dyspepsia were performed did we begin to recognize more fully that while peptic ulcer disease (PUD) was disappearing, GERD with or without EE was becoming the commonest cause of dyspepsia. Yet, some patients with typical heartburn and regurgitation had a completely normal endoscopy. Over time, this concept became further modified by the recognition that the sensitivity of optical endoscopy could be improved with magnification, and that some persons with "endoscopy normal reflux disease" (ENRD), also known as "normal endoscopy reflux disease" (NERD), had pathological changes on esophageal biopsy. Perhaps it would have been more appropriate if NERD had been "non-erosive reflux disease". So, the PUD-associated focus on the ulcer was transferred to the assessment of the severity of EE, but the acceptance of NERD as part of the legitimate spectrum of GERD forced the initially somewhat grudging acceptance of the importance of symptoms in assessing the role of PPIs in all persons with GERD.

\section{What is GERD?}

What is GERD? GERD is “.... a chronic, relapsing disease that infrequently progresses but is associated with a range of potentially serious esophageal complications (esophageal ulcer, esophageal stricture, Barrett's esophagus or esophageal cancer) and extra-esophageal diseases such as respiratory problems, chest pain, angina, and increased mortality" (Ruigomez et al 2004; Sontag et al 2006; Scholten et al 2007). Other authors have suggested that GERD is "a condition which develops when the reflux of stomach contents causes troublesome symptoms and/or complications" (Vakil et al 2006). The more recent Montreal consensus definition states that GERD is "a condition that develops when the reflux of gastric contents causes troublesome symptoms, impairs quality of life ( $Q$ of $L$ ) or leads to mucosal damage or complications". Symptoms of GERD may overlap with functional dyspepsia (FD) and irritable bowel syndrome (IBS) (Quigley et al 2007), so these must be taken into account as possible GERD-associated symptoms. Indeed, IBS-like symptoms are seen in 19\%-71\% of persons with GERD, and GERD-like symptoms are seen in 33\%-75\% of persons with IBD. It is speculated that this overlap may be due to visceral hypersensitivity in GERD, FD, and IBS (Bardhan et al 2004a; Beckerling et al 2004; Achim et al 2005a, b).

\section{What are the optimal outcome measures to assess GERD treatment?}

The recently developed ReQuest ${ }^{\mathrm{TM}}$ assessment of symptoms of GERD, and its amalgamation with the Los Angeles (LA) classification of erosive esophagitis (EE) have been used to provide an assessment tool which led to the development of a new concept in GERD, that of "complete healing." What is so new about "complete healing" in GERD? It is recognized that from a symptom perspective, GERD is much more than heartburn and regurgitation: in GERD there are esophageal, supra-esophageal as well as infra-esophageal symptoms, all contributing to the patient's impaired Q of L.

In addition, there is a disassociation between the severity of the patient's dyspeptic symptoms, and the severity of the underlying EE; in fact, there is only a limited correlation between the severity of endoscopic esophagitis and the severity and frequency of reflux symptoms (Wiklund 1988, 2001; Holtmann et al 2001; Dent et al 2005). For example, about half of individuals with dyspeptic symptoms may have a normal endoscopy (Modlin et al 2007). Endoscopically normal reflux disease was defined by the Genval Workshop 
Report (Armstrong et al 2004; Bardhan et al 2004a, b; Monnikes et al 2004; Stanghellini 2004b) as "GERD in patients who have no endoscopic evidence of Barrett's esophagus or esophageal mucosal breaks."(Armstrong et al 2004, Bardhan et al 2004a, b; Monnikes et al 2004; Stanghellini et al 2004a). These persons have typical GERD symptoms caused by refluxed gastric contents, in the absence of visible esophageal mucosal injury as assessed by esophagogastroendoscopy (EGD) (Armstrong et al 2004; Bardhan et al 2004a, b; Monnikes et al 2004; Stanghellini 2004; Stanghellini et al 2004). Indeed, the symptom profile does not help the clinician to distinguish between NERD and EE, without there first being an EGD performed. Thus, in all GERD patients, including those with NERD, symptom assessment in response to therapy is important.

Furthermore, in studies reporting on the clinical improvement in the symptoms of GERD in subjects with EE, data will often be given of the proportion of persons improving or losing their symptoms, and the proportion of persons improving or losing their esophagitis. But these are not necessarily the same individuals who both improve and who their endoscopic signs of disease. Why might this be important? A high proportion of GERD patients have an improvement or resolution of both symptoms and signs of their disease after 4-8 weeks' therapy with a PPI, and yet unless they are maintained on continuous use PPI, many will have a recurrence of disease (approximately 80\% in 6-12 months). We do not know whether persons with a given level of symptoms or endoscopic signs might heal completely in 4 rather than 8 or 12 weeks of therapy.

Is there a subgroup of GERD patients, possibly as assessed by suitable measures of symptoms and endoscopic grade, who may be managed without maintenance PPI therapy and have a high probability of remaining in remission? On the other hand, is there an identifiable subgroup that needs to be maintained on full rather than half dose PPI? Furthermore, are there GERD sufferers who need longer periods of PPI treatment in order to enjoy complete resolution of their symptoms and normalization of their esophagus on endoscopy? The answers to these questions have important clinical and economic considerations. But more than that, perhaps if complete healing were achieved (in terms of both symptoms and where applicable, endoscopic signs), might the recurrence rate be lower, the need for maintenance PPI be less, and the patients' Q of L be better? These are important and yet unresolved questions, that could not be studied until an appropriate assessment tool became available recently.
There is a small but appreciable treatment response to placebo in persons with GERD, with improvement in symptoms and signs in the patient in a clinical trial who is given placebo to compare with the outcome of acid lowering therapy. At the time of endoscopic study, the patient with previous EE may have fully or partially healed esophagitis. We know, for example from studies of prompt endoscopy in persons with previously undiagnosed dyspepsia where previous recent use of acid-lowering therapy was forbidden, that the proportion of subjects with more severe EE (LA C and D) is low (about 5\%) (Thomson et al 2003), and yet in a long-term care facility the proportion of LA C and D subjects was 3- to 4-fold higher (Thomson et al 2003). In addition, reconsideration of the efficiency and safety of so-called "on demand" therapy as a maintenance strategy for GERD has shown us that $0 \%-94 \%$ will have EE on subsequent EGD (Kuster et al 1994; Isolauri et al 1997; Manabe et al 2002; Pace et al 2004; Labenz et al 2006; Sontag et al 2006). It is controversial whether this relates to the natural history of GERD becoming endoscopically positive or negative, rather than NERD being a distinct non-continuum component of the GERD disorder (Fass et al 2001). Finally, even in persons with NERD, there may be subtle abnormalities when the mucosa is assessed by magnifying endoscopy or mucosal biopsy (Kiesslich et al 2004; Kato et al 2007). Thus, it is not clear that a so-called "normal" esophageal mucosa on EGD is in fact representative of tissue that is truly normal at the microscopic or even biochemical level.

\section{Why do we need a new GERD questionnaire?}

This question is raised in the title of a recent systematic review (Armstrong et al 2004) and has been considered in recent single topic monograph reviews (Armstrong et al 2004; Stanghellini 2005; Bardhan et al 2007; Beckerling et al 2007; Monnikes et al 2007). Unfortunately, much time passed before it was accepted that the cluster of dyspeptic symptoms did not predict the cause of the patient's pain or discomfort in the upper abdomen: persons with heartburn and regurgitation did not necessarily have EE on EGD, pain in the epigastric area improving or worsening with food and awakening the patient from sleep did not necessarily signify PUD, and symptoms of fullness, nausea and bloating were not necessarily associated with a normal EGD, and thus were speculated to be part of a motility disorder. This lack of correlation between symptoms and the causes of dyspepsia forced the reconsideration of the importance of all dyspeptic symptoms as possibly being part of the spectrum of GERD. 
Indeed, there was even the need to refine what we mean by the term "heartburn", and accept that in some cultures there is no translation for this word. Vigorous discussions even ensued as to whether dyspepsia and GERD symptoms were one-in-the-same: Some of the arguments considered the observations that some persons with typical GERD symptoms often have NERD; indeed, typical "ulcer-like" symptoms were more likely to be associated with EE than with PUD; and there is extensive overlap in the symptoms of EE, PUD, and NERD (also sometimes previously called non-ulcer dyspepsia [NUD], or functional dyspepsia [FD]). It was no wonder then that there was much discussion about the semantics, and no surprise that the resulting confusion prevented us for so long from taking a step back, looking outside the box, and appreciating that what was important to the sufferer of GERD was the treatment-associated improvement in their troublesome symptoms: leave the EGD findings to the endoscopist, and focus on the patient's symptomatology.

Let us consider a shift in primary outcomes - endoscopists and therefore clinical trialists were quite able to reasonably accurately measure the diameter of a DU or GU, and we then became reasonably comfortable with the qualitative assessment of the severity of EE, using a variety of scales of damage, such as the new widely used LA or modified LA scale (the same as the original LA A-D scale of EE, but including a descriptor for GERD symptoms but a normal endoscopy). However, one challenge remained: there is no tight correlation between the severity of the GERD symptoms and the severity of EE. For example, from the severity of symptoms, the clinician cannot predict whether the EGD will be normal, whether there will be EE present, or what will be the severity of any associated LA A-D esophagitis. This was an issue with the use of H2-RAs, since these agents were slower and less effective than the PPIs in healing EE. But with the PPIs, all grades of EE from LA A to D are usually healed using standard unit doses of PPI once a day for $4-8$ weeks. Healing of
EE became an end in itself, not because this was necessarily associated with complete resolution of symptoms, but rather because it was expected that such healing would reduce the frequency and/or severity of stricture formation or reformation, or the development or even progression of Barrett's epithelium, and therefore reduce the risk of development of dysplasia and esophageal adenocarcinoma. Such hopes have not always been substantiated. So, if healing of EE is not necessary for symptom improvement or complication prevention, then why aim to always achieve endoscopic healing of EE? Furthermore, EE may recur without symptoms, and symptom recurrence does not necessarily signify EE recurrence. Thus, when GERD symptoms recur, there may be the same, less, or more EE.

When a new therapeutic agent is being considered for formulary approval, a number of considerations are made, including safety and efficacy of symptom improvement, healing of associated pathological changes, enhancement of $Q$ of $L$, and cost. Different clinical trials will use various symptom scales, and not all of these have been validated for the GERD disease setting, nor are the healing of associated pathological changes, necessarily comparable. For example, of the 20 symptom assessment scales, only 5 have been evaluated (Table 1). Before symptom scales or $Q$ of $L$ instruments can be accepted as primary endpoints by investigators, health-care decision-makers, or government/insurance payers, the scales must be evaluated to document their validity, reliability and responsiveness. Bardhan et al (2004b) have summarized the importance of psychometric validation: psychometric validation is essential for instruments used to assess surrogate markers (for example, GERD symptoms or $\mathrm{Q}$ of L), particularly when they are designed to be used as the primary outcome measure in clinical trials comparing two or more treatments. Two statements from the International Conference on Harmonization guidelines make the points: 1) when a rating scale is used as the primary variable, it

Table I Main characteristics of the identified evaluative symptom scales

\begin{tabular}{lllllll}
\hline Name & GERD-specific & Multidimensional & Self-assessed & Daily assessed & $\begin{array}{l}\text { Available in different } \\
\text { languages }\end{array}$ & $\begin{array}{l}\text { Psychometrically } \\
\text { validated }\end{array}$ \\
\hline GERD Score & $\checkmark$ & - & - & - & - & $\checkmark$ \\
UESS & - & $\checkmark$ & $\checkmark$ & - & - & $\checkmark$ \\
GSAS & $\checkmark$ & $\checkmark$ & $\checkmark$ & - & - & $\checkmark$ \\
GSRS & - & - & $\checkmark$ & - & $\checkmark$ & $\checkmark$ \\
GRACI & $\checkmark$ & - & $(\checkmark)^{*}$ & $(\checkmark)^{*}$ & - & - \\
\hline
\end{tabular}

Abbreviations: GERD, gastroesophageal reflux disease; GRACI, GERD Activity Index; GSAS, GERD Symptom Assessment Scale; GSRS, Gastrointestinal Symptoms Rating Scale; UESS, Ulcer Esophagitis Subjective Symptoms Scale.

*Only parts of the scale. 
is especially important to address factors such as content validity, inter- and intra-rater reliability and responsiveness for detecting changes in the severity of the disease; and 2) if a trial ... lacks assay sensitivity, it will fail to lead to a conclusion of efficacy. In contrast ..., the trial may find an ineffective treatment to be non-inferior and could lead to an erroneous conclusion of efficacy.

Specific aspects of GERD symptomatology need to be considered, especially when using generic versus diseasespecific questionnaires. But what in fact are the symptoms of GERD? Does the instrument measure esophageal as well as supra- and/or infra-esophageal symptoms, in addition to Q of L? Who administers the questionnaire, the health care worker or the patient? And what is the inter- and intra-investigator variability? Because so many large trails today are multicentre and multinational, does the assessment instrument translate well into various languages? What is the "background noise" of the score obtained in the questionnaire in normal persons not presenting with GERD? Because about half of GERD subjects have a normal endoscopy, then response to treatment cannot be measured by changes in the severity of erosions, and the availability of a validated, reliable and sensitive instrument to assess the symptoms, Q of $\mathrm{L}$ and response to therapy is therefore important (Armstrong et al 2004; Bardhan et al 2004a).

Stanghellini et al systemically reviewed symptom scales for GERD from the perspective of their characteristics and psychometric quality, as well as the wide range of GERD symptoms. They considered what should be the main features of a valid symptom scale, what should be measured, when symptoms should be measured, and who should assess the symptoms (Table 2). Symptom measurement tools should be discriminative, predictive or evaluative instruments: "A discriminative instrument is intended to distinguish between patient groups, and to classify them according to the prevailing symptoms, including their severity and frequency. If the assessment tool is to be used for diagnostic purposes, a discriminative questionnaire must be highly specific for the disease in question, whilst excluding other diseases with a high prediction probability. A predictive scale is used of a gold standard is available to estimate the likelihood of a specific disease or risk factors under defined circumstances. An evaluative scale is used to measure the magnitude of change in symptom severity, eg, over time, in one person, or in a group of persons. Its prime requirement is responsiveness, although validity and reproducibility are also necessary" (Stanghellini et al 2004, p. 4). The evaluative scale could be used, for example, to compare the results of
Table 2 Recommendations for an ideal GERD symptom assessment instrument suitable as a primary end-point for clinical trials

I. be sensitive in patients with GERD

2. cover the frequency and intensity of typical and atypical GERD symptoms

3. be multi-dimensional (cover all symptom dimensions)

4. have proven psychometric properties (validity, reliability, and responsiveness)

5. be practical and economic

6. be self-assessed (self-administered)

7. use "word pictures" which are easy to understand for patients

8. respond rapidly to changes (responsiveness over short time intervals)

9. be used daily to assess changes during and after therapy

10. be valid in different languages for international use

Adapted with permission from Bardhan KD, Berghofer P. 2007. Look - but also listen! ReQuest ${ }^{\text {Th }}$ :An essay on a new validated scale to assess the outcome of GERD treatment. Digestion, 75(Suppl):87-100. Copyright $\odot 2007$ S. Karger AG.

one clinical trial with another. Because there are numerous symptoms experienced by GERD patients, and because the distribution of these symptoms may vary with the severity of EE (Table 3), a new assessment method is needed.

This review by Stanghellini et al (2004) demonstrated that 5 of the evaluative symptom scales did not fulfill all of the recommendations for an evaluative symptom scale (Table 1) (Stanghellini et al 2004) For example, only 3 of 5 were GERD specific, 2 were multidimensional, 3 were self-assessed, 1 was assessed daily, 1 was available in different languages, and 4 were psychometrically validated (Stanghellini et al 2004) Given the limitations of the currently available evaluative symptom scales, there is clearly a need for a new evaluative symptom tool for the assessment of GERD symptoms during therapy, a scale that can be used in clinical trials of different therapeutic agents, to appropriately compare the treatment outcome of one medication with another. The ReQuest ${ }^{\circledR}$ questionnaire shows reliability, validity and ability to detect change; an ideal measurement instrument must be able "to determine the minimum change measured which has true "clinical relevance" as judged by the patient and his or her doctor" (Bardhan and Berghofer 2007, p. 99).

From a consideration of the literature, few evaluative scales fulfill even some of these key characteristics. The GERD Symptom Assessment Scale is the most comprehensive evaluative symptom scale to date (Stanghellini et al 2004, 2006). It is a well-validated 15 -item scale that includes associated as well as predominant GERD symptoms. It also assesses different symptom dimensions (frequency of episodes, intensity of symptoms, level of distress), and it is self-assessed twice, once before and once after treatment. However, this scale does not assess nocturnal symptoms of 
Table 3 ReQuest ${ }^{\mathrm{TM}}$ : Validation (statistical results)

\begin{tabular}{|c|c|c|c|c|c|}
\hline \multirow[t]{2}{*}{ Statistical test } & \multirow[t]{2}{*}{ What the test assesses } & \multirow{2}{*}{$\begin{array}{l}\text { Range } \\
\text { of results }\end{array}$} & \multirow{2}{*}{$\begin{array}{l}\text { Results: Threshold } \\
\text { that needs } \\
\text { to be exceeded } \\
\text { or matched }\end{array}$} & \multicolumn{2}{|c|}{ Results obtained } \\
\hline & & & & $\begin{array}{l}\text { erosive } \\
\text { esophagitis }\end{array}$ & $\begin{array}{l}\text { non erosive } \\
\text { reflux }\end{array}$ \\
\hline Cronbach's alpha & Internal consistency & 0 to 1 & $>0.70$ & 0.90 & 0.91 \\
\hline $\begin{array}{l}\text { Intra-class correlation } \\
\text { coefficient }\end{array}$ & Test-retest reliability* & 0 to 1 & $>0.70$ & $\begin{array}{l}\text { LQ } 0.94 \\
\text { SQ } 0.86\end{array}$ & $\begin{array}{l}\text { LQ } 0.89 \\
\text { SQ } 0.78\end{array}$ \\
\hline Construct validity & $\begin{array}{l}\text { Correlation of prototype } \\
\text { against existing instruments }\end{array}$ & $-\mid$ to $\mid$ & Approximately \pm 0.5 & $\begin{array}{l}\text { GSRS } 0.52 \\
\text { PGWB }-0.48 \\
\text { (Spearman } \\
\text { coefficient) }\end{array}$ & $\begin{array}{l}\text { GSRS } 0.55 \\
\text { PGWB }-0.39 \\
\text { (Pearson } \\
\text { coefficient) }\end{array}$ \\
\hline Responsiveness index & $\begin{array}{l}\text { Quantifies the ability to measure } \\
\text { GERD symptom changes } \\
\text { as a result of treatment }\end{array}$ & 0 to infinity & $>0.80$ & 165 & 320 \\
\hline
\end{tabular}

Abbreviations: *Reproducibility of the LQ \& SQ is tested: LQ vs LQ, LQ vs SQ, SQ vs LQ, SQ vs SQ, LQ, Long questionnaire; SQ, short questionnaire; GSRS, gastrointestinal symptom rating scale; PGWB, pshchological general well being index scale. Reproduced with permission from Bardhan KD, Berghofer P. 2007. Look - but also listen! ReQuest ${ }^{\text {tw: }}$ An essay on a new validated scale to assess the outcome of GERD treatment. Digestion, 75 (Suppl): 87-100. Copyright @ 2007 S. Karger AG.

GERD, and it has not been tested in multinational clinical trials. Thus, there is only limited information on its responsiveness and transcultural validity. The Gastrointestinal Symptom Rating Scale (GSRS) is an evaluative, patientrated symptom scale, which is one of the most widely used GI-specific symptom scales in various settings (Achim et al 2005a; Fass et al 2005; Stanghellini 2005). It was initially constructed for the evaluation of symptom severity in persons with peptic ulcer disease and irritable bowel syndrome, and hence, it is not specific for GERD. All other evaluative symptom scales described in the literature have limitations such as lack of proven validity, are not self-assessed, comprise only predominant symptoms, or were developed for other purposes (Monnikes et al 2004; Achim et al 2005b; Beckerling et al 2007).

It is important to appreciate that a quarter to half of GERD patients do not have heartburn (Armstrong et al 2004; Bardhan et al 2004a; Stanghellini et al 2004; Monnikes et al 2007) and about half of GERD patients have additional symptoms without having predominant heartburn (Armstrong et al 2004; Bardhan et al 2004a, b; Monnikes et al 2004; Stanghellini et al 2004). Only about a fifth of patients with EE have heartburn during reflux episodes (Armstrong et al 2004; Bardhan et al 2004a, b; Monnikes et al 2004; Stanghellini 2004; Stanghellini et al 2004; Beckerling et al 2004). The specificities of heartburn and regurgitation are $89 \%$ and $95 \%$, respectively, but the sensitivities are only about $38 \%$ and $6 \%$, respectively (Klauser et al 1990), or even lower when there are atypical symptoms (Armstrong et al 2004; Bardhan et al 2004a; Beckerling et al 2004;
Bardhan et al 2004b, 2005; Monnikes et al 2004, 2005a; Stanghellini 2004; Stanghellini et al 2004, 2005, 2006). Persons with GERD have a plethora of esophageal as well as supra- and infra-esophageal symptoms, and these may respond less predictably than do heartburn and regurgitation to acid-lowering therapy (Armstrong et al 2004; Bardhan et al 2004a, b, 2005; Monnikes et al 2004; Beckerling et al 2004; Schoffel et al 2004; Stanghellini 2004; Stanghellini et al 2004, 2005, 2006; Monnikes et al 2005a). It is possible that in the presence of predominant heartburn or regurgitation, these other symptoms may not be fully appreciated, and once the predominant symptoms are improved with therapy, the associated symptoms become more prominent. On the other hand, it is possible that once the predominant symptoms are improved, the associated symptoms become less bothersome, and are perceived to be milder.

GERD symptoms are episodic, and may vary even on a daily basis. For example, Kartman et al (2004) reported that there is a $40 \%$ probability that symptom levels will differ on successive days (Galmiche et al 1998; Jasani et al 1999). Thus, in a clinical trial, it is important for the symptoms to be assessed frequently, ideally on a daily basis, rather than just at the beginning and at the arbitrary end of the study. Finally, there is a poor inter-observer reliability of symptom assessment when physicians rather than the patients administer a questionnaire (Rothman et al 2001) and self-assessment may be more reliable than external assessments (Locke et al 1994; Rentz et al 2001). For example, physicians tend to underestimate the severity of patients' symptoms (Stephens et al 1997). 
The standards to be met in developing an instrument for teaching changes in GERD symptom in therapeutic trials have been summarized (Bardhan and Berghofer 2007). These standards recommended for an ideal GERD symptom assessment instrument suitable as a primary end-point for clinical trials are outlined in Table 2. ReQuest ${ }^{\mathrm{TM}}$ has been subjected to validation using psychocentric testing and statistical testing (Cronbach's alpha, intra-class correlation co-efficient, construct validity, and responsiveness index (Bardhan and Berghofer 2007) (Table 3).

Thus, the conceptual and psychometric requirements for a GERD symptom assessment questionnaire have been identified (Armstrong et al 2004). In the next section (Section 3) is described the development of such an ideal tool, the ReQuest ${ }^{\mathrm{TM}}$ scale.

\section{Development of the new questionnaire, ReQuest ${ }^{\mathrm{TM}}$}

The frequency and intensity of symptoms of GERD are poor predictors of the presence or severity of endoscopic changes (Ofman et al 2002; Johnson and Fennerty 2004). From a practical perspective, it has been suggested that GERD may be present when the person has heartburn on two or more days a week (Dent et al 1999). The primary aim of GERD treatment should be normalization of the sufferer's quality of life through rapid and sustained resolution of esophageal and other GERD-associated symptoms (Revicki et al 1999). Secondarily, any associated esophagitis should be healed in the hope of fewer symptomatic recurrences, and the prevention of the development or progression of complications such as strictures, Barrett's epithelium, and esophageal adenocarcinoma. The treatment of GERD accomplishes the aim of improving symptoms, health-related Q of L, and mucosal healing (Prasad et al 2003).

The steps in the development of ReQuest ${ }^{\mathrm{TM}}$ have been reviewed (Armstrong et al 2004). GERD symptoms are heterogeneous, episodic and subjective (Modlin et al 2007). This becomes a matter of concern about the assessment of GERD symptoms in clinical trials, if symptom assessment is based only on the eradication of limited symptoms such as heartburn (which is itself often poorly defined) and if symptom assessment is made only, at fixed time points such as study entry, (time 0), and at 2 and 4 weeks. Furthermore, in many clinical trials in GERD, the members investigative team rather than the patient assess the symptom response to PPI therapy (the patient's perspective is the most important, and may be under-estimated by the investigators (Rothman et al 2001)).
In the first step of the development of the ReQuest ${ }^{\mathrm{TM}}$ GERD questionnaire, the symptom spectrum of GERD and various symptom descriptions were investigated. To design ReQuest $^{\mathrm{TM}}$, all identified items typical (GERD symptoms and GERD-related complaints) from the literature and the interview surveys were reviewed. Different ways of describing the same thing were removed, leaving 67 items which were assigned to 6 different symptom dimensions (acid complaints, upper abdominal/stomach complaints, lower abdominal/digestive complaints, nausea, sleep disturbances, and other complaints).

A short and a long version of ReQuest ${ }^{\mathrm{TM}}$ was developed. In the short version, the frequency of the dimensions was assessed using a 7-point Likert scale, and the intensity of the dimensions was assessed using a 100 -mm visual analogue scale. The use of the Likert-type responses has been shown to produce higher internal consistency than dichotomized responses (Beckerling et al 2004; Monnikes et al 2004; Bardhan et al 2004b, 2005; Gillessen et al 2004; Naumburger et al 2004; Stanghellini 2004, 2005b, 2006; Monnikes et al 2005a). General well-being was added, and its intensity was assessed. A hierarchic logical order was used, reflecting clinical practice, starting with the dimensions and then proceeding to the details. The symptom burden of the dimensions was measured by its frequency and/or intensity. The questionnaire was translated into different languages and then tested in focus groups. The first step at validation was to perform an open study in 421 outpatients in Germany with endoscopically confined EE (LA grades A-D) given pantoprazole $20 \mathrm{mg}$ daily for LA A, and pantoprazole $40 \mathrm{mg}$ daily for LA B-D (BB 3,4). The long and short versions of the scale were applied on days $-3,0,7,14,21$, and 28 , and on all other days, respectively. A second early clinical trial tested the prototype in 840 patients with NERD in Europe and Canada (Bardhan and Berghofer 2007).

The initial German version was translated into British English, American English, French and Spanish, using forward-, reconciliation-, and backward-translations. Focus group testing was undertaken in cities in 5 countries, and a preliminary validation of ReQuest ${ }^{\mathrm{TM}}$ was conducted in an open, multicentre German study. "The current version of ReQuest $^{\mathrm{TM}}$ retained 60 of the original 67 items after factor analysis, ie, 7 symptom descriptions contributed little to the GERD symptom spectrum. These 60 items were clustered into 20 factors, and these in turn correlated with the dimensions. Condensing items into dimensions is a pragmatic empirical process, whereas factor analysis is a mathematical one." The factor analysis for the identification of items that did not load 
was performed 4 times. The dimensions were grouped into two subscales: the subscale ReQuest ${ }^{\mathrm{TM}}$-GI which reflected acid complaints, stomach complaints, digestive complaints, and nausea, and the subscale ReQuest ${ }^{\mathrm{TM}}$-WSO which included the other dimensions reflecting the aspects of well-being (general well-being, sleep disturbances and other complaints). The symptom pattern varies in patients with different endoscopic GERD grades (Table 4) (Bardhan et al 2007). For example, lower abdominal/digestive complaints and sleep disturbances are more prevalent in LA D than in LA A. The greatest symptom changes occurred during the first week of treatment with pantoprazole 20 and $40 \mathrm{mg}$, with the largest and most rapid decline being in the dimensions of acid and upper abdominal/ stomach complaints (Figure 1) (Bardhan et al 2004a).

The second phase of development of ReQuest ${ }^{\mathrm{TM}}$ was based on the data from the open study in 421 patients mentioned above and included internal consistency, test-rated reliability, and responsiveness (Monnikes et al 2004). Construct validity was studied by comparison with the GSRS and the Psychological General Well-Being (PGWB) scale. Validation of ReQuest ${ }^{\mathrm{TM}}$ indicated a very high internal consistency (Cranbach's $\infty=0.90$ ) and test-related reliability (in correlation coefficient 0.94 [long-term] and 0.86 [short-term]). This was also the case for the two subscales of ReQuest ${ }^{\mathrm{TM}}-\mathrm{GI}$ and ReQuest ${ }^{\mathrm{TM}}-\mathrm{WSO}$, with Cranbach's $\infty$ coefficients of 0.84 and 0.81 , respectively. Responsiveness was high, with a responsiveness index of $>0.8$ at day 28. Construct validity was good. Of importance, there was no association between the initial endoscopic GERD grade and the degree of correlation, indicating that the intensity of symptom load appears to be independent of the severity of the endoscopic grade. As noted previously, a similar lack of correlation of clinical symptoms and endoscopic signs has been reported previously (Klauser et al 1990; Beckerling et al 2004; Monnikes et al 2004, 2005a; Gillessen et al 2004; Schoffel et al 2004; Bardhan et al 2004b, 2005; Stanghellini 2004, 2005b, 2006; Van Resburg et al 2005).

In addition to the ReQuest ${ }^{\mathrm{TM}}$ questionnaire (Stanghellini et al 2005), a GERD specific questionnaire has been developed to assess health-related Q of L (Holtmann et al 2005). These two sensitive and specific questionnaires have been used to assess the GERD patient's satisfaction with PPI (Ferguson et al 2006).

\section{Establishing a definition of symptom relief}

ReQuest $^{\mathrm{TM}}$ is being studied for its possible use to detect the minimum clinically important difference (MCID) in symptoms in GERD patients in PPIs. In clinical trials, "symptom relief", or time to first or sustained symptom relief may be used, but mild background symptoms may occur (Bardhan and Berghofer 2007). A more stringent endpoint therefore is reduction of symptoms to below the background

Table 4 Complete remission, endoscopically confirmed healing and symptom relief rates (\%) after 4, 8, and I2 weeks

\begin{tabular}{|c|c|c|c|c|c|c|}
\hline \multirow[b]{3}{*}{ Treatment } & \multicolumn{6}{|c|}{ Duration of treatment } \\
\hline & \multicolumn{2}{|l|}{4 weeks } & \multicolumn{2}{|l|}{8 weeks } & \multicolumn{2}{|l|}{12 weeks } \\
\hline & ITT & PP & ITT & PP & ITT & PP \\
\hline \multicolumn{7}{|c|}{ Complete remission } \\
\hline Pantoprazole & 47 & 59 & 69 & 86 & $76^{\dagger}$ & $93^{\dagger}$ \\
\hline Esomeprazole & 49 & 62 & 70 & 84 & $76^{+}$ & $90^{\dagger}$ \\
\hline $\mathrm{Cl}$ & {$[-10.4,+\infty]$} & {$[-12.2,+\infty]$} & {$[-8.0,+\infty]$} & {$[-4.6,+\infty]$} & {$[-7.0,+\infty]$} & {$[-2.9,+\infty]$} \\
\hline \multicolumn{7}{|l|}{$\begin{array}{l}\text { Endoscopically } \\
\text { confirmed healing }\end{array}$} \\
\hline Pantoprazole & 69 & 75 & 86 & 94 & 91 & $98^{*}$ \\
\hline Esomeprazole & 69 & 75 & 83 & 90 & 98 & $94^{*}$ \\
\hline $\mathrm{Cl}$ & {$[-7.39,7.69]$} & {$[-8.08,8.55]$} & {$[-3.01,8.68]$} & {$[-0.80,9.59]$} & {$[-1.75,9.59]$} & {$[0.02,7.27]$} \\
\hline \multicolumn{7}{|l|}{ System relief } \\
\hline Pantoprazole & 63 & 76 & 77 & 90 & 79 & 95 \\
\hline Esomeprazole & 64 & 78 & 75 & 89 & 77 & 92 \\
\hline $\mathrm{Cl}$ & {$[-8.8,6.9]$} & {$[-10.2,6.0]$} & {$[-5.3,8.6]$} & {$[-4.9,6.8]$} & {$[-4.7,8.8]$} & {$[-1.8,7.9]$} \\
\hline
\end{tabular}

Abbreviations: ITT, intention to treat; PP, per-protocol; $\mathrm{Cl}$, confidence interval of the difference.

*superiority of pantoprazole $(\mathrm{Cl}$ above 0$)$; ${ }^{\dagger}$ primary outcome criterion. Reproduced with permission from Bardhan KD, Achim A, Riddermann T et al 2007. A clinical trial comparing pantoprazole and esomeprazole to explore the concept of achieving 'complete remission' in gastro-oesophageal reflux disease. Aliment PharmacolTher, 25: I46I-69. Copyright (C) 2007 Blackwell Publishing Ltd. 

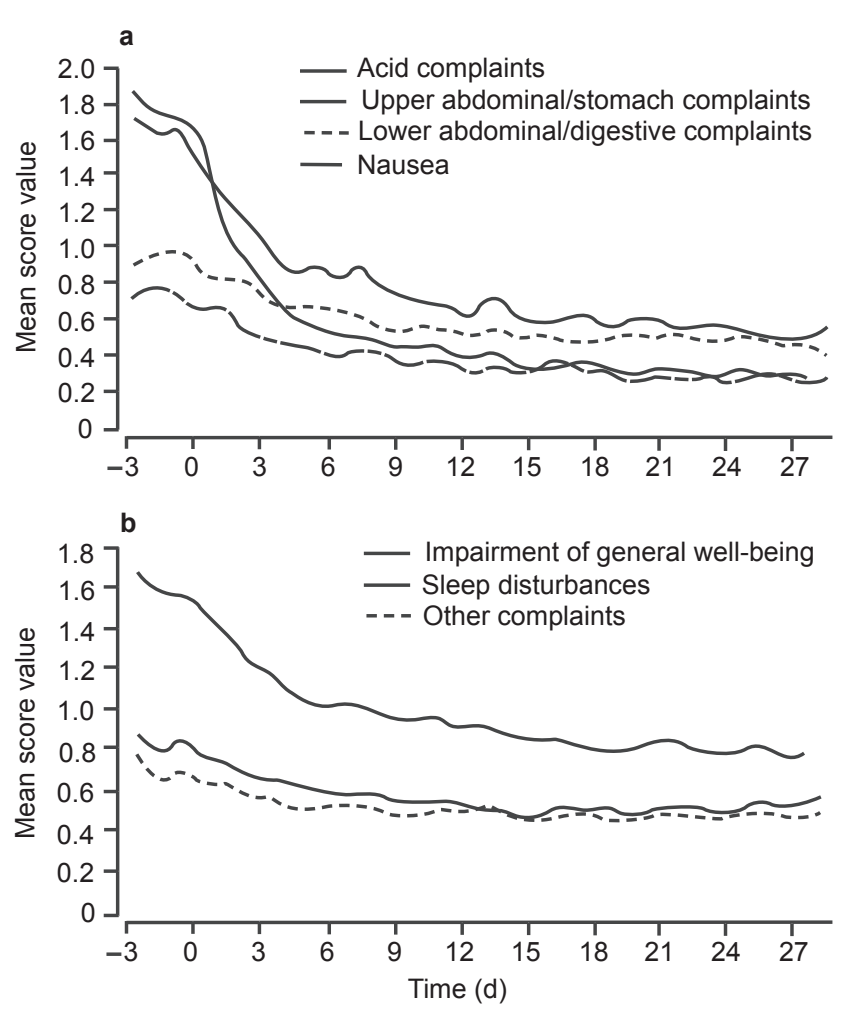

Figure I Changes in gastro-oesophageal reflux disease (GORD) related symptoms as assessed by ReQuest ${ }^{\mathrm{TM}}$ in an intention to treat population of 421 patients with GORD during treatment with pantoprazole $20 \mathrm{mg} /$ day (Los Angeles [LA] Grade A) or $40 \mathrm{mg} /$ day (LA grades B-D). Reproduced with permission from Bardhan KD, Stanghellini V, Armstrong D, et al. 2004a. Evaluation of GERD symptoms during therapy. Part I. Development of the new GERD questionnaire ReQuest. Digestion, 69:229-37. Copyright (c) 2004 S. Karger AG.

level. The GERD symptom threshold was determined (Achim et al 2005b): the GERD symptom thresholds (95th percentile) in 385 healthy Germans was: ReQuest ${ }^{\mathrm{TM}}$, 5.04; ReQuest-GI, 1.73; ReQuest - WSO, 3.88. In 2,032 subjects from the US, France, Spain, and Italy (Klauser et al 1990), similar scores were obtained (4.12, 1.60, and 2.87 , respectively).

What is the symptom threshold, using ReQuest ${ }^{\mathrm{TM}}$, to define symptom relief in GERD studies where the endoscopy is either negative or positive? To answer this question, Stanghellini et al (2005a) recruited 385 individuals over the age of 18 , who did not consider themselves as suffering regularly from GERD symptoms, and who were not taking any medications for GERD. The intensity and frequency of seven dimensions of GERD symptoms were determined in these healthy volunteers, to calculate the ReQuest ${ }^{\mathrm{TM}}$, ReQuest ${ }^{\mathrm{TM}}$ GI, and ReQuest ${ }^{\mathrm{TM}}$-WSO scores. The participants also completed the GSRS as well as the PGWB scale. The GERD symptom threshold was calculated as the 90th percentile of the ReQuest ${ }^{\mathrm{TM}}$ score in this population without evidence of GERD. GERD symptom thresholds were 3.37 for ReQuest ${ }^{\mathrm{TM}}$, 0.95 for ReQuest ${ }^{\mathrm{TM}}-\mathrm{GI}$, and 2.46 for ReQuest ${ }^{\mathrm{TM}}-\mathrm{WSO}$.
This is an important concept, allowing the definition of what is in fact the normal range and upper limit of the ReQuest ${ }^{\mathrm{TM}}$ scores. This thereby establishes a benchmark for the definition of "symptom relief" in future treatment studies. It is therefore sufficient to treat GERD patients until symptom burden is below the GERD symptom threshold seen in healthy persons.

A generally accepted definition of symptomatic relief in GERD was missing in the medical literature until the ReQuest ${ }^{\mathrm{TM}}$ tool was developed (Beckerling et al 2004). As pointed out by Beckerling et al (2004) the aim of GERD therapy is to achieve symptom relief and healing of esophageal lesions. The importance of both of these endpoints was considered, and the steps in the development of the ReQuest ${ }^{\mathrm{TM}}$ symptom score were reviewed.

The next step was to develop the ReQuest ${ }^{\mathrm{TM}} / \mathrm{LA}$ Classification, a novel integrated approach for the comprehensive assessment of treatment outcome in GERD (Bardhan et al 2005). The LA classification of $E E$ has four degrees of abnormality: A, B, C, and D. The ReQuest ${ }^{\mathrm{TM}}$ investigators added a fifth grade, LA N (LA Normal), the common situation where EE is not present (ie, NERD). The validated subscale ReQuest ${ }^{\mathrm{TM}}$-GI was rescaled to develop the ReQuest ${ }^{\mathrm{TM}}$ Symptom Classification. Using log-linear regression, a transformation of ReQuest ${ }^{\mathrm{TM}}$-GI score was performed to establish a grading from 0 to 4 , reflecting the influence of symptoms on patients' well-being ( 0 : no disease value, score $0-1.70 ; 1$ : minor, score $1.71-3.79 ; 2$ : tolerable, score 3.80-8.43; troublesome, score 8.44-18.75; 4: intense, score 18.76-30.76). A matrix of ReQuest ${ }^{\mathrm{TM}} / \mathrm{LA}$ Classification had both symptomatic and endoscopic classifications to provide an integrative index quantifying both relevant aspects of the clinical situation by identifiers from $0 \mathrm{~N}$ (symptoms: No disease value; lesions: Not present) to 4D (symptoms: Intense; lesions: Grade D) (Fass et al 2005). The authors suggest that "the new index enables the detailed clinical characterization of GERD patients at any stage and accurate assessment of treatment outcome by a single global measure. Furthermore, the index allows a standardized clinical assessment and a simplified comparison of the results of different clinical trials."

\section{Use of ReQuest ${ }^{\mathrm{TM}}$ in GERD patients with a normal endoscopy}

"A shift in the management model from targeting structural abnormalities [minimal change esophagitis to LA A-D] and one dominant symptoms in GERD [eg heartburn] to focusing on the identification and quantification of a broad spectrum of symptoms [as in ReQuest ${ }^{\mathrm{TM}}$ ] has led to a reconsideration of our 
current concepts of GERD" (Modlin et al 2007; Quigley et al 2007). Indeed, the Genval workshop suggested that the definition of NERD includes persons with symptoms of GERD but who have not endoscopic evidence of erosion, ulceration or Barrett's esophagus (Thomson et al 2003). Fass et al have defined NERD patients as having GERD symptoms, normal mucosa at EGD, plus acidic or weekly acidic intraesophageal reflux (Fass et al 2001). High-resolution magnification EGD has demonstrated various subtle changes at the squamocolumnar function of GERD patients with normal conventional EGD (Kiesslich et al 2004). This has led to the term "minimal change esophagitis" (Nakamura et al 2005).

About a quarter fewer NERD patients respond to a given symptomatic treatment compared with those GERD patients with esophageal erosions (Fass 2007). For example, Dean et al (2004) demonstrated in a systematic review that the PPI symptomatic pooled rate was 36.7 (95\% confidence interval [CI]: 34.1-39.3) in NERD patients and $55.5(95 \%$ C1: 51.5-59.5) in those with EE. Therapeutic gain was $27.5 \%$ in NERD compared with $48.9 \%$ in EE. NERD patients' symptoms respond equally to half as to full dose PPI, unlike those who have erosive esophagitis (Richter et al 2000). In 529 subjects with GERD symptoms but normal EGD (NERD) treated with P20 or E20, the median time to first relief was 2 days, and 10-13 days for sustained relief (again, ITT, not statistically significant (Monnikes et al 2007).

\section{Use of ReQuest ${ }^{\mathrm{TM}}$ in GERD patients with erosive esophagitis (EE)}

The placebo-response of GERD symptoms and EE is low. Initial studies with PPIs were focused on showing that they were superior to placebo or to H2-RAs in symptom improvement and EE healing. Then the commercial challenge was to demonstrate whether one PPI gave superior symptom control or EE healing than a competitor's PPI. Clinical trials attempting to show the superiority of PPI-A versus PPI-B in healing EE can generally be achieved only with enrolment of thousands of GERD patients, the difference between the two healing rates is small, and the number of persons needed to treat (NNT) to achieve this superiority is large (eg, NNT of 15-20). The ability of a trial to show a difference in EE healing rates is also influenced by the proportion of subjects with more severe esophagitis (LA C/D), since healing rates with LA A/B are already so high $(>90 \%)$, that there is little room for improvement and therefore little opportunity for the delta value between the therapeutic benefit of the two PPIs (PPI-A, PPI-B) to be statistically significant.
The open study initially used to validate ReQuest ${ }^{\mathrm{TM}}$ comprised 421 endoscopy-positive GERD patients (ie, EE present), with a comparison of 2 doses of pantoprazole (Bardhan et al 2004; Monnikes et al 2004). Then, a doubleblind, randomized, parallel-group comparison was undertaken in 45 centers across Germany, with 529 NERD patients treated with $20 \mathrm{mg}$ pantoprazole or $20 \mathrm{mg}$ esomoprazole over 4 weeks (Monnikes et al 2007). Using ReQuest ${ }^{\mathrm{TM}}$ in these patients with endoscopically normal GERD, there was no difference in the two treatments in terms of median time for the patients to achieve symptom relief ( 2 days for both pantoprazole and esomoprazole), and to sustained symptom relief (10 vs 13 days, $\mathrm{p}>0.05$, powered to evaluate noninferiority). Furthermore, no statistically significant differences were observed between the two treatment groups in the response to treatment according to the associated Heliobacter pylori status (Monnikes et al 2007). Symptom relief was defined as a ReQuest ${ }^{\mathrm{TM}}$ sum score below the GERD symptom threshold, as attained in Section 4 (recall that the symptom threshold had precisely been determined in a separate study of individuals without GERD) (Stanghellini et al 2005a). This approach is more precise than the simple presence or absence of one or more particular symptoms since it incorporates multiple symptom dimensions instead of single items, and was assessed daily by the patient rather than only at one point at the end of the 28-day treatment period.

\section{Comparison of pantoprazole 20 or $40 \mathrm{mg}$ to placebo}

A randomized, double-blind, multicenter, parallel-group comparison was performed in 386 patients with erosive GERD LA B-D (Monnikes et al 2005b). Treatment was for 4 weeks. The values of clinically important differences for sum scores of ReQuest ${ }^{\mathrm{TM}}$ and ReQuest ${ }^{\mathrm{TM}}$-GI were significantly different for pantoprazole versus placebo.

\section{Comparison of pantoprazole $40 \mathrm{mg}$ vs omeprazole $20 \mathrm{mg}$}

Therapy was given to 261 matched pairs of symptomatic GERD patients, with endoscopic esophagitis scores of LA B-D (Naumburger et al 2004) As assessed by ReQuest ${ }^{\mathrm{TM}}$ and by the patient assessment of general well-being after 1 and 2 weeks of therapy, pantoprazole (P) $40 \mathrm{mg}$ daily was significantly superior to omeprazole (O) $20 \mathrm{mg}$ daily. Patients enjoyed a significantly lower symptom level with $\mathrm{P} 40$ versus O20 from day 2 onwards, and first time to reach normal symptoms was achieved about 2 days faster in the pantoprazole than in the omeprazole group $(p=0.0298)$. Furthermore, 
154 in the P40 group and 139 in the $\mathrm{O} 20$ group had sleep disturbances at baseline. Patients treated with P40 suffered from less sleep disturbances after 1 and 2 weeks of therapy, as compare with those give O20 (Schoffel et al 2004). Data on healing rates of the associated EE were not provided.

\section{Comparison of pantoprazole vs esomoprazole}

\section{Initial treatment}

In a community based study of per protocol (PP) persons with dyspepsia undergoing EGD before being placed on therapy, approximately $45 \%$ had erosive esophagitis, $5 \%$ had peptic ulcer disease, and the remainder had a normal endoscopy (Thomson et al 2003). The prevalence of LA C/D esophagitis was approximately $10 \%$. So, for every 1,000 dyspeptics, 450 would have EE, of which 45 would have severe esophagitis, LA C/D.

In 529 patients with endoscopy-negative GERD receiving $20 \mathrm{mg}$ pantoprazole or $20 \mathrm{mg}$ esomeprazole, ReQuest ${ }^{\mathrm{TM}}$ symptoms scores were assessed daily for 14 days (Bardhan and Berghofer 2007; Monnikes et al 2007). The median time to first symptom relief was 2 days for both drugs (ITT population), and the median time to sustained symptom relief (10 vs 13 days) was not significantly different between the treatment groups.

In 561 ITT patients with LA A-D GERD, non-inferiority of pantoprazole vs esomeprazole $40 \mathrm{mg}$ daily was shown (Glatzel et al 2007). However, the persons treated with pantoprazole for 28 days may have enjoyed "better healing", since when PPI therapy was stopped, during the 7 day post treatment period, the proportion of patients experiencing a symptomatic relapse (51 vs $61 \%, p=0.0216$, ITT) and the number of symptomatic episodes ( 0.56 vs $0.71, \mathrm{p}=0.0095$, ITT) were significantly lower on pantoprazole than on esomeprazole. In 2,316 persons with erosive esophagitis with either pantoprazole $40 \mathrm{mg}$ (P40) or esomeprazole $40 \mathrm{mg}$ (E40) daily, the median time to first symptom relief was 2 days, and 5-6 days for sustained relief(ITT population, differences between P40 and E40 not statistically significant (Bardhan and Berghofer 2007).

A total of 581 symptomatic subjects with LA A-D EE were randomized to pantoprazole $40 \mathrm{mg}$ (P40) or esomoprazole $40 \mathrm{mg}$ (E40) for 12 weeks in a double-blind, multicenter, parallel group comparison (Bardhan et al 2007). Symptom relief was considered to have been achieved if the score of the ReQuest ${ }^{\mathrm{TM}}$-GI fell below the predefined upper limit of the GERD symptom threshold. Neither on an ITT or a PP basis was there a difference between pantoprazole vs esomeprazole in complete remission, endoscopically confirmed healing or symptom relief (Table 4) Symptom relief at 4, 8, and 12 weeks was similar in the two treatment arms, both on an intention-to-treat (ITT) and a per protocol basis (Achim et al 2005a) The endoscopic healing rates on an ITT basis were similar in P40 and E40 at 4, 8, and 12 weeks, but P40 was higher than E40 PP healing rates at 12 weeks. Including all subjects (LA A-D), the reduction in P40 was numerically but not statistically superior to E40 after 12 weeks of treatment ( $p=0.059)$, but for patients LA B-D, $\mathrm{P} 40$ was superior to $\mathrm{E} 40$ ( $\mathrm{p}=0.0029)$. Using the cumulative rates of complete remission (Bardhan et al 2005a) P40 was non-inferior to $\mathrm{E} 40$ at 4, 8, and 12 weeks.

Interestingly, in both treatment arms, a proportion of patients were inadequately treated after 8 weeks of therapy, with higher values of complete remission at 12 vs 8 weeks. This concept of the need for some subjects to be treated longer was strengthened by an open study of 934 LA A-D GERD subjects (Heading et al 2006). Treatment was for a maximum of 12 weeks, unless complete remission was achieved at 4 or 8 weeks (Gok et al 2007). There was an inverse relationship between the LA esophagitis grade and the complete remission rate at 4, 8, and 12 weeks (Table 5). Approximately one third of GERD LA B-D subjects had not achieved complete remission after 8 weeks treatment, and treatment for 12 weeks gave higher complete remission rates of $77.6 \%-82.7 \%$ (Table 6). Thus, it is clear that there is a sizable proportion of GERD patients who need 12 rather than the usual 8 weeks of PPI therapy in order to achieve complete healing, heating and symptom relief (Table 7).

The ReQuest ${ }^{\mathrm{TM}}$ database contains baseline and treatment data from 14 clinical trials with symptom assessment

Table 5 Symptom pattern in patients with different endoscopic GERD grades given as mean total score values dimension load

\begin{tabular}{lllll}
\hline $\begin{array}{l}\text { Dimension } \\
\text { of ReQuest }^{\text {TM }}\end{array}$ & $\begin{array}{l}\text { Grade A } \\
(\mathbf{n}=\mathbf{1 8 2})\end{array}$ & $\begin{array}{l}\text { Grade B } \\
(\mathbf{n}=\mathbf{1 3 0})\end{array}$ & $\begin{array}{l}\text { Grade C } \\
(\mathbf{n}=\mathbf{3 3})\end{array}$ & $\begin{array}{l}\text { Grade D } \\
(\mathbf{n}=\mathbf{4})\end{array}$ \\
\hline Acid complaints & $85.2^{*}$ & 82.3 & 81.8 & 100 \\
$\begin{array}{l}\text { Upper abdominal/ } \\
\text { stomach complaints }\end{array}$ & 75.8 & 73.9 & 75.8 & 75.0 \\
$\begin{array}{l}\text { Lower abdominal/ } \\
\text { digestive complaints }\end{array}$ & 57.1 & 47.7 & 57.6 & 75.0 \\
$\begin{array}{l}\text { Nausea } \\
\text { Sleep disturbances }\end{array}$ & 65.4 & 59.2 & 60.6 & 100 \\
Other complaints & 61.0 & 63.9 & 57.6 & 75.0 \\
\hline
\end{tabular}

* Mean total score values, dimension load = frequency times intensity per protected, 349 patients at baseline. After Heading et al 2006. 
Table 6 Complete remission rates (\%) after 4, 8, and 12 weeks (per protocol population)

\begin{tabular}{llll}
\hline Patient group & $\mathbf{4}$ weeks & $\mathbf{8}$ weeks & 12 weeks \\
\hline NERD & 64 & 83 & 90 \\
Grade A esophagitis & 62 & 81 & 88 \\
Grade B esophagitis & 43 & 66 & 83 \\
Grades C/D esophagitis & 32 & 64 & 78 \\
\hline
\end{tabular}

After Heading et al 2006.

based on the reflux questionnaire ReQuest ${ }^{\mathrm{TM}}$. The trials were designed to show the effect of different treatment regimens on symptom patterns in different patient populations (Thomson and Peter 2007). Demography and baseline characteristics between the two treatment groups were similar. Within the tested population $(\mathrm{N}=3967)$ the mean scores for the acid dimension and the ReQuest ${ }^{\mathrm{TM}}$-GI for patients treated with pantoprazole $40 \mathrm{mg}$ and esomeprazole $40 \mathrm{mg}$ were lower on day 28 than at baseline (Table 8). In the acid dimension scores the mean pre-post differences were $-2.12( \pm 2.01)$ for pantoprazole $40 \mathrm{mg}$ and $-2.12( \pm 2.12)$ for esomeprazole 40 $\mathrm{mg}$, resulting in a $9 \%$ difference between the pre-post difference values (Table 8). The differences between the scores of ReQuest ${ }^{\mathrm{TM}}$-GI were $-5.33( \pm 5.38)$ for pantoprazole $40 \mathrm{mg}$ and $-4.44( \pm 4.97)$ for esomeprazole $40 \mathrm{mg}$ (ie, 17\%). For both scores the mean pre-post difference for patients treated with pantoprazole $40 \mathrm{mg}$ significantly exceeded the values for esomeprazole $40 \mathrm{mg}(\mathrm{p}<0.0001)$.

The patient population was divided into groups following the LA classification for grades of GERD. Here, identical effects as for the whole study population were found for the dimension acid complaints. In the group of patients with GERD grade A the mean pre-post differences were -1.97 ( \pm 1.94$)$ for pantoprazole $40 \mathrm{mg}$ and -1.78 ( \pm 1.90) for esomeprazole $40 \mathrm{mg}$ (ie, 10\%). Patients with GERD grade B showed pre-post differences of $-2.49( \pm 2.02)$ in the pantoprazole $40 \mathrm{mg}$ treatment group and -1.87 ( \pm 1.90$)$ in the esomeprazole $40 \mathrm{mg}$ treatment group, respectively (ie, 25\%). The pre-post differences for patients with GERD grades $C$ and D were $-2.43( \pm 2.03)$ for pantoprazole $40 \mathrm{mg}$ and $-2.05( \pm 2.03)$ for esomeprazole $40 \mathrm{mg}$ (ie, $16 \%$ ). In all subgroups defined by GERD grade, the mean pre-post differences for patients treated with pantoprazole $40 \mathrm{mg}$ were significantly higher that the differences for esomeprazole $40 \mathrm{mg}(\mathrm{p}<0.0001$ to $\mathrm{p}=0.046)$ (Table 9).

The use of ReQuest ${ }^{\mathrm{TM}}$ questionnaire led to the greater appreciation of the importance of supra- and infra- esophageal symptoms, and the diversity of esophageal symptoms in persons with GERD, all of which impair the patients' Q of L. The development of ReQuest ${ }^{\mathrm{TM}}$ questionnaire to asses both symptoms of GERD, QofL, and endoscopic changes based on the LA A-D grading of erosive esophagitis, led to the concept of complete healing, and pointed our attention to the potential need to treat some GERD patients for 12 weeks, or perhaps even longer. Recently presented studies published as yet only in abstract form highlight even more conceptual changes arising out of the ReQuest ${ }^{\mathrm{TM}}$ program: IBS symptoms are significantly more frequent in NERD than in GERD patients with EE, and symptom burden is more severe in NERD with IBS than in EE with IBS (Monnikes et al 2008). Patients whose GI symptoms respond well to treatment tend to have a lesser overall symptom burden, a lesser quality of life impairment, and less psychological distress before treatment than those who respond less well to 4 to 8 weeks PPI therapy (Heading et al 2008). Finally, ReQuest ${ }^{\mathrm{TM}}$ and its subscales ReQuest-61 ${ }^{\mathrm{TM}}$ and ReQuest-WSO ${ }^{\mathrm{TM}}$ were assessed in 1888 GERD patients before therapy with pantoprazole $40 \mathrm{mg} \mathrm{OD}$, and then at 4 and 8 weeks of therapy. A logistic regression was used to develop a model which predicted the response to PPI treatment with a probability of up to $80 \%$ (Heading et al 2008).

In summary, in the reporting of clinical trials, notes of healing of esophagitis and symptom relief are often reported separately, but when subjects with both healing and symptom relief are identified, the percentages are lower than when each component is reported separately. This speaks to the importance of complete remission, and begs the question whether off-therapy recurrence rates are lower in those with complete healing, versus those with just symptom relief, or with endoscopic healing. This is but one of the many ways in which the ReQuest ${ }^{\mathrm{TM}}$ scale may be very useful in the design of future clinical trials. Now that the simplified ReQuest in Practice ${ }^{\circledR}$ (Rubin et al 2008) is available, this validated brief questionnaire "...has potential as an instrument for use in GERD patients," seen in everyday clinical practice.

Table 7 Endpoints of symptom relief or healing at 4, 8, or 12 weeks

\begin{tabular}{llll}
\hline Rates & $\mathbf{4}$ & $\mathbf{8}$ & $\mathbf{1 2}$ \\
\hline Symptom relief & 77 & 90 & 93 \\
Healing rates & 75 & 92 & 96 \\
Complete healing & 61 & 85 & 81 \\
\hline
\end{tabular}

After Heading et al 2006. 
Table 8 Mean pre-post differences between baseline and after 28 days of treatment

\begin{tabular}{lllll}
\hline & Panto $40 \mathrm{mg}$ & Eso $40 \mathrm{mg}$ & $\Delta \%$ & p-value \\
\cline { 2 - 5 } & Mean & Mean & & \\
& score (SD) & score (SD $)$ & & \\
\hline Acid dimension & $-2.32( \pm 2.0 \mathrm{I})$ & $-2.12( \pm 2.12)$ & 9 & $<0.000 \mathrm{I}$ \\
ReQuest $^{\mathrm{T}}$-GI & $-5.33( \pm 5.38)$ & $-4.44( \pm 4.97)$ & 17 & $<0.000 \mathrm{I}$ \\
\hline
\end{tabular}

After Thomson and Peter 2007.

aStandard deviation.

\section{Concluding remarks}

Perhaps it is worthwhile to take a historical perspective: initially acid-lowering therapy was used to manage patients with the then much more common cause of dyspepsia, PUD. The healing of the crater of the duodenal (DU) or gastric ulcer (GU) became the sought-after endpoint; symptom relief was often seen as being quite secondary. As the inclusion of Q of L assessment slowly began to be included in the clinical trials of PPIs in PUD, the Nobel prize-winning recognition of the cure of many DU or GUs with the eradication of H. pylori, and the acknowledgement of the importance of the pathophysiological components providing gastro protection, lead to the greater use of co-therapy in high risk persons taking aspirin (ASA), non-steroidal anti-inflammatory agents (NSAIDs), or coxibs. These two factors contributed to the already declining prevalence of DU/GU. Curiously, GERD slowly became more widely recognized, but the same narrow mindset that early on prevented some clinicians from accepting the role of $H$. pylori and NSAIDs in PUD, also prevailed initially in the design of PPI studies in patients with GERD.

"Other than in research studies, there [is] no pressing need for its use [ie, EGD] in day-to-day clinical practice to make the diagnosis of GERD or to distinguish between the different categories" (Bardhan and Berghofer 2007 p. 89).

Table 9 Mean acid dimension pre-post differences for GERD grades at baseline and after 28 days of the treatment

\begin{tabular}{lllll}
\hline & Panto $40 \mathrm{mg}$ & Eso $40 \mathrm{mg}$ & $\Delta \%$ & p-value \\
\cline { 2 - 5 } LA Grade & Mean score (SD $)$ & Mean score & & \\
\hline A & $-1.97( \pm 1.94)$ & $-1.78( \pm 1.90)$ & 10 & 0.046 \\
B & $-2.49( \pm 2.02)$ & $-1.87( \pm 1.90)$ & 25 & $<0.0001$ \\
C/D & $-2.43( \pm 2.03)$ & $-2.05( \pm 2.03)$ & 16 & 0.025 \\
\hline
\end{tabular}

After Thomson and Peter 2007.

astandard deviation.
The proportion of persons with reflux symptoms who have a normal endoscopy (ENRD) ranges from about 50\% to $75 \%$ (Johansson et al 1986; Winters et al 1987; Jones et al 1995; Lind et al 1997; Carlsson et al 1998; Galmiche et al 1998; Ronkainen et al 2005).

The ReQuest ${ }^{\mathrm{TM}}$ database includes 14 clinical studies with 8,177 GERD patients in the ITT and 6,810 in the per protocol PP, comparing P40 with E40. ReQuest ${ }^{\mathrm{TM}}$ allowed the identification of 1) a greater reduction the frequency and severity of symptoms on day 1 with P40 compared with E40 (32); 2) in patients with erosive esophagitis, there were fewer episodes of reflux on P40 than E40 (33); $3)$ on day 28 of PPI treatment, there was a greater reduction in ReQuest-GI with P40 than E40 (Goh et al 2007); and 4) greater reduction in sleep disturbance with P40 than E40 (Kato at al 2007).

Comparisons of large numbers of GERD subjects with erosive esophagitis have suggested, in post-randomization analysis, numerically higher healing rates of E40 versus P40 or L30 (lansoprazole $30 \mathrm{mg}$ daily (REF, REF). If these differences were as great as $70 \%$ for $\mathrm{E} 40$ and $50 \%$ for $\mathrm{P} 40$ / L30, then 32/45 would heal on E40, and 23/45 would heal on the other PPIs.

Thus, 9/1,000 persons on E40 might possibly have a higher erosive healing rate, giving an NNT of about 100 . If the number of persons in the community with $\mathrm{EE}$ were lower, or if the difference between healing rates for LA-C/D between two PPIs were less than $20 \%$, the NNT would be even higher. Because of such a high value for NNT, it is no surprise that some governmental, professional or regulatory agencies have suggested that there is no clinically important difference between the PPIs. Whether this statement is true with the application of ReQuest/LA, and complete remission, remains to be established.

A maintenance study of 1450 GERD LA A-D patients initially treated 4-8 weeks on $\mathrm{P} 40$, randomization for the purpose of maintenance was undertaken with P20 or E20, and follow-up was 6 months (Kato et al 2007). No difference was seen in the treatment groups. In the Emancipate study (Goh et al 2007), 1303 patients with symptomatic LA A-D EE (were treated for healing of EE and "no" or "mild" heartburn and acid regurgitation) were randomized in a double blind manner for maintenance with pantoprazole $20 \mathrm{mg}$ (P20) or esomeprazole $20 \mathrm{mg}$ (E20) once daily for 6 months.

\section{Acknowledgments}

The author wishes to express his sincere thanks for the excellent editorial assistance of Ms. Lori Ingram. 


\section{Disclosures}

The author reports no conflicts of interest.

\section{Abbreviations}

ASA, acetylsalicylic acid (aspirin); CI, confidence interval; DU, duodenal ulcer; E40 mg, esomeprazole 40 mg; EE, erosive esophagitis; EGD, esophagogastroduodenoscopy; ENRD, endoscopy normal reflux disease; FD, functional dyspepsia; GERD, gastroesophageal reflux disease; GI, gastrointestinal; GSRS, Gastrointestinal Symptom Rating Scale; GU, gastric ulcer; IBS, irritable bowel syndrome; ITT, intent-to-treat (population); L30 mg, lansoprazole 30 mg; LA, Los Angeles; MCID, minimal clinically important difference; NERD, normal endoscopy reflux disease; NNT, needed to treat; NSAID, nonsteroidal anti-inflammatory drugs; NUD, non-ulcer dyspepsia; P40 mg, pantoprazole 40 mg; PGWB, Psychological General Well-Being; PP, patient population; PPI, proton pump inhibitor; PUD, peptic ulcer disease; Q of L, quality of life.

\section{References}

Achim A, Riddermann T, Pfaffenberger B, et al. 2005. Pantoprazole $40 \mathrm{mg}$ is at least comparable to esomeprazole $40 \mathrm{mg}$ in achieving endoscopically confirmed healing and symptom relief of gastroesophageal reflux disease (GERD) after 4, 8 and 12 weeks of treatment. Can J Gastroenterol, 19 (Suppl C):DR.0038.

Achim A, Riddermann T, Bethke TD, et al. 2005. A new integrated approach for assessing the effectiveness of pantoprazole and esomeprazole treatment in patients with gastroesophageal reflux disease (GERD). Gastroenterology, 4(Suppl 2):A-528.

Armstrong D, Monnikes H, Bardhan KD, et al. 2004. The construction of a new evaluative GERD questionnaire - methods and state of the art. Digestion, 70:71-8.

Bardhan K, Achim A, Riddermann T, et al. 2005. Achieving complete remission in patients with erosive gastroesophageal reflux disease (GERD): pantoprazole is comparable with esomeprazole. Gut, 54(Suppl VII):A-106.

Bardhan KD, Achim A, Riddermann T et al. 2007. A clinical trial comparing pantoprazole and esomeprazole to explore the concept of achieving 'complete remission' in gastro-oesophageal reflux disease. Aliment Pharmacol Ther, 25:1461-9.

Bardhan K, Armstrong D, Fass R, et al. 2005. The ReQuest ${ }^{\mathrm{TM}}$ LA-classification: a novel integrated approach for the comprehensive assessment of treatment outcome of gastroesophageal reflux disease (GERD). Can J Gastroenterol, 19(Suppl C): R.0031.

Bardhan KD, Berghofer P. 2007. Look - but also listen! ReQuest ${ }^{\mathrm{TM}}$ : An essay on a new validated scale to assess the outcome of GERD treatment. Digestion, 75(Suppl):87-100.

Bardhan KD, Stanghellini V, Armstrong D, et al. 2004a. Evaluation of GERD symptoms during therapy. Part I. Development of the new GERD questionnaire ReQuest. Digestion, 69:229-37.

Bardhan KD, Stanghellini V, Armstrong D, et al. 2004b. International validation of ReQuest in patients with endoscopy-negative gastrooesophageal reflux disease. Aliment Pharmacol Ther, 20:891-8.

Beckerling A, Braun W, Sommer M. 2007. Process of measuring in clinical medicine - implications of different definitions in clinical therapeutic studies. Digestion, 75(Suppl 1):25-31.

Carlsson R, Dent J, Watts R, et al. 1998. Gastro-oesophageal reflux disease in primary care: an international study of different treatment strategies with omeprazole. International GORD Study Group. Eur J Gastroenterol Hepatol, 10:119-24.
Dean BB, Gano AD Jr, Knight K, et al. 2004. Effectiveness of proton pump inhibitors in nonresponsive reflux disease. Clin Gastroenterol Hepatol, 2:656-64.

Dent J, Brun J, Frederick AM, et al. 1999. An evidence-based appraisal of reflux disease management - the Genval Workshop Report. Gut, 44(Suppl 2):S1-S16.

Dent J, Brun J, Frederick AM, et al. 2004. An evidence-based appraisal of reflux disease: workshop background, processes, terminology, has proved to be a challenging task. Any accurate recommendations and discussion outputs. Gut, 53(Suppl 4):iv1-24.

Dent J, El-Serag HB, Wallander MA et al. 2005. Epidemiology of gastrooesophageal reflux disease: a systematic review. Gut, 54(5):710-7.

Dimenas E, Glise H, Hallerback B, et al. 1993. Quality of life in patients with upper gastrointestinal symptoms. An improved evaluation of treatment regimens? Scand J Gastroenterol, 28:681-7.

Dimenas E, Carlsson G, Glise H, et al. 1996. Relevance of norm values as part of the documentation of quality of life instruments for use in upper gastrointestinal disease. Scand J Gastroenterol Suppl, 221:8-13.

Enck P, Dubois D, Marquis P. 1999. Quality of life in patients with upper gastrointestinal symptoms: results from Domestic/International Gastroenterology Surveillance Study (DIGEST). Scand J Gastroenterol Suppl, 231:48-54.

Fass R, Fennerty MB, Vakil N. 2001. Nonerosive reflux disease - current concepts and dilemmas. Am J Gastroenterol, 96:303-14.

Fass R, Berghofer P, Gatz G, et al. 2005. Symptom pattern determines the time to first symptom relief in erosive esophagitis (EE) patients treated with a proton pump inhibitor (PPI). Gut, 54(Suppl VII):A-109.

Fass R. 2007. Erosive esophagitis and nonerosive reflux disease (NERD) comparison of epidemiologic, physiologic, and therapeutic characteristics. J Clin Gastroenterol, 41:131-7.

Ferguson DD, DeVault KR, Krishna M, et al. 2006. Enhanced magnification directed biopsies do not increase the detection of intestinal metaplasia in patients with GERD. Am J Gastroenterol, 101:1611-6.

Gallup. 1988. A Gallup Organization National Survey: Heartburn Across America. Princeton: The Gallup Organization Inc.

Galmiche JP, Barthelemy P, Hamelin B. 1997. Treating the symptoms of gastro-oesophageal reflux disease: a double-blind comparison of omeprazole and cisapride. Aliment Pharmacol Ther, 11:765-73.

Galmiche JP, Letessier E, Scarpignato C. 1998. Treatment of gastrooesophageal reflux disease in adults. Br Med J, 316:1720-3.

Gillessen A, Schoffel L, Naumburger A, et al. 2004. Symptomatic relief with pantoprazole $40 \mathrm{mg}$ is significantly faster than with omeprazole 20 mg. Gut, 53(Suppl VI):A103.

Glatzel D, Abdel-Qader M, Gatz G, et al. 2006. Pantoprazole $40 \mathrm{mg}$ is as effective as esomeprazole $40 \mathrm{mg}$ to relieve symptoms of gastroesophageal reflux disease after 4 weeks of treatment and superior regarding the prevention of symptomatic relapse. Digestion, 74:145-54.

Gok K-L, Benazoumig R, Sander P, et al. 2007. Efficacy of pantoprazole $20 \mathrm{mg}$ daily compared with esomeprazole $20 \mathrm{mg}$ in the maintenance of healed gastroesophageal reflux disease: a randomized, double-blind comparative trial- the EMANCIPATE study. Eur J Gastroenterol Hepatol, 19:205-11.

Heading RC, Bardhan KD, Sander P, et al. 2006. Application of the complete remission concept: Many patients with GERD are incompletely treated by a standard proton pump inhibitor (PPI) regime. Gut, 55(Suppl V):A 62.

Heading RC, Berghofer P, Doerfler $\mathrm{H}$ et al. 2008. Interactions of GERDrelated symptoms, Health-related quality of life and anxiety and depression in GERD patients treated with a PPI. Am Gastroenterol Assoc.

Holtmann G. 2001. Reflux disease: the disorder of the third millennium. Eur J Gastroenterol Hepatol, 13(Suppl 1):55-11.

Holtmann G. 2005. Understanding GERD symptoms in clinical setting. Drugs Today (Barc), 41(Suppl B):13-7.

Isolauri J, Luostarinen M, Isolauri E, et al. 1997. Natural course of gastroesophageal reflux disease: $17-22$ year follow up of 60 patients. Am J Gastroenterol, 92:37-41. 
Jasani K, Piterman L, McCall L. 1999. Gastroesophageal reflux and quality of life. Patient's knowledge, attitudes, and perceptions. Aust Fam physician, 28 (Suppl 1):S15-8.

Johansson KE, Ask P, Boeryd B, et al. 1986. Oesophagitis, signs of reflux and gastric acid secretion in patients with symptoms of gastrooesophageal reflux disease. Scand J Gastroenterol, 21:837-47.

Johnson DA, Fennerty MB. 2004. Heartburn severity underestimates erosive esophagitis severity in elderly patients with gastroesophageal reflux disease. Gastroenterology, 126:660-4.

Jones RH, Hungin AP, Phillips J, et al. 1995. Gastro-esophageal reflux disease in primary care in Europe: clinical presentation and endoscopic findings. Eur J Gen Pract, 1:149-54.

Kaplan-Machlis B, Spiegler GE, Revicki DA. 1999. Health-related quality of life in primary care patients with gastro esophageal reflux disease. Ann Pharmacother, 33:1032-6.

Kartman B, Gatz G, Johannesson M. 2004. Health state utilities in gastroesophageal reflux disease patients with heartburn: a study in Germany and Sweden. Med Decis Making, 24:40-52.

Kato M, Ono S, Nakagawa M et al. 2007. Endoscopic examination including magnifying endoscopy for diagnosis of GERD. Nippon Rinsho, 65:865-71.

Kiesslich R, Kanzler S, Vieth M, et al. 2004. Minimal change esophagitis: prospective comparison of endoscopic and histological markers between patients with non-erosive reflux disease and normal controls using magnifying endoscopy. Digestive Diseases, 22:221-7.

Klauser AG, Schindlebeck NE, Müller-Lissner SA. 1990. Symptoms in gastro-oesophageal disease. Lancet, 335:205-8.

Kleinman L. Leidy NK, Crawley J, et al. 2001. A comparative trial of paper-and-pencil versus computer administration of the Quality of Life in Reflux and Dyspepsia (QOLRAD) questionnaire. Med Care, 39:181-9.

Kuster E, Ros E, Toledo-Pimentel V, et al. 1994. Predictive factors of the long-term outcome in gastroesophageal reflux disease: six year follow up of 107 patients. Gut, 35:8-14.

Labenz J, Arnstrong D, Lauritsen K, et al. 2006. Esomeprazole $20 \mathrm{mg}$ vs. pantoprazole $20 \mathrm{mg}$ for maintenance study of healed therapy erosive esophagitis: results from the EXPO study. Aliment Pharmacol Ther, 23:449.

Lind T, Havelund T, Carlsson R, et al. 1997. Heartburn without oesophagitis: efficacy of omeprazole therapy and features determining therapeutic response. Scand J Gastroenterol, 32:974-9.

Locke GR, Talley NJ, Weaver AL, et al. 1994. A new questionnaire for gastroesophageal reflux disease. Mayo Clin Proc, 69:539-47.

Locke G III, Talley NJ, Fett SL, et al. 1997. Prevalence and clinical spectrum of gastroesophageal reflux: a population-based study in Olmsted County, Minnesota. Gastroenterology, 112:1448-56.

Malfertheiner P, Fass R, Quigley EM, et al. 2006. Review article: from gastrin to gastro-oesophageal reflux disease - a century of acid suppression. Aliment Pharmacol Ther, 23:683-90.

Manabe N, Yoshihara M, Sasaki A, et al. 2002. Clinical characteristics and natural history of patients with low-grade reflux esophagitis. Gastroenterrol Hepatol, 17:949-54.

Modlin IM, Malfertheiner P, Hunt RH, et al. 2007. GERD evaluation: time for a new paradigm? J Clin Gastroenterol, 41:237-41.

Monnikes H, Bardhan KD, Stanghellini V, et al. 2004. Evaluation of GERD symptoms during therapy. Part II. Psychometric evaluation and validation of the new questionnaire ReQuest in erosive GERD. Digestion, 69:238-44.

Monnikes H, Pfaffenberger B, Gatz G, et al. 2005. Novel measurement of rapid treatment success with ReQuestTM: first and sustained symptom relief as outcome parameters in patients with endoscopy-negative GERD receiving $20 \mathrm{mg}$ pantoprazole or $20 \mathrm{mg}$ esomeprazole. Digestion, 71:152-8.

Monnikes H, Berghofer P, Gatz G, et al. 2005. First determination of the clinically important difference of ReQuest ${ }^{\mathrm{TM}}$ sum scores in patients with erosive gastroesophageal reflux disease (GERD) by comparison of active treatment versus placebo. Gut, 54(Suppl VII):A-108.
Monnikes H, Bardhan KD, Stranghellini V. 2007. Evaluation of GERD symptoms during therapy. Part II. Psychometric evaluation and validation of the new questionnaire ReQuest ${ }^{\mathrm{TM}}$ in erosive GERD. Digestion, 75(Suppl 1):41-7.

Monnikes H, Doerfler H, Schmitt H, et al. 2008. Is the response of GERD patients to PPI therapy affected by the presence of IBS-like symptoms? Am Gastroenterol Assoc.

Nakamura T, Shirakawa K, Masuyama H, et al. 2005. Minimal change oesophagitits: a disease with characteristic differences to erosive oesophagitis. Aliment Pharmacol Ther, 21:19-26.

Naumburger A, Schoffel L, Gillessen A. 2004. Comparison of two treatment regimens in symptomatically homogenous GERD patient populations: pantoprazole relieves gastrointestinal symptoms significantly better than omeprazole. Gut, 53(Suppl VI):A108.

Nebel OT, Fornes MF, Castell DO. 1976. Symptomatic gastroesophageal reflux: incidence and precipitating factors. Am J Dig Dis, 21: 953-6.

Ofman JJ, Dorn GH, Fennerty MB, et al. 2002. The clinical and economic impact of competing management strategies for gastro-oesophageal reflux disease. Aliment Pharmacol Ther, 16:261-73.

Pace F, Bollani S, Molteni P, et al. 2004. Natural history of gastrooesophageal reflux disease without oesophagitis (NERD) - a reappraisal 10 years on. Dig Liver Dis, 36:111-5.

Pare P, Armstorng D, Pericak D, Mmath, et al. 2003. Pantoprazole rapidly improves Health-Related Quality of Life in patients with heartburn: a prospective randomized, double blind comparative study with Nizatidine. J Clin Gastroenterol, 37:132-8.

Prasad M, Rentz AM, Revicki DA. 2003. The impact of treatment for gastro-oesophageal reflux disease on health-related quality of life: a literature review. Pharmacoeconomics, 21:769-90.

Quigley E, Heading R, Monnikes H. 2007, Exploring the spectrum of GERD myths and realities. Ann Gastroenterol, 20:155-63.

Rentz AM, Battista C, Trudeau E, et al. 2001. Symptom and health-related quality-of-life measures for use in selected gastrointestinal disease studies. Pharmacoeconomics, 19:349-63.

Revicki DA, Crawley JA, Zodet MW, et al. 1999. Complete resolution of heartburn symptoms and health-related quality of life in patients with gastrooesophageal reflux disease. Ailment Pharmacol Ther, 13:1621-30.

Richter JE, Campbell DR, Kahrilas PJ, et al. 2000. Lansoprazole compared with ranitidine for the treatment of nonerosive gastroesophageal reflux disease. Arch Intern Med, 160:1803-9.

Ronkainen J, Aro P, Storskrubb T, et al. 2005. High prevalence of gastroesophageal reflux symptoms and esophagitis with or without symptoms in the general adult Swedish population: a Kalixanda study report. Scand J Gastroenterol, 40:275-85.

Rothman M, Farup C, Stewart W, et al. 2001. Symptoms associated with gastroesophageal reflux disease: development of a questionnaire for use in clinical trials. Dig Dis Sci, 46:1540-9.

Rubin G, Uebel P, Brimo-Hayek A. 2008. Validation of a brief symptom questionnaire (ReQuest in Practice ${ }^{\mathrm{TM}}$ ) for patients with gastroesophageal reflux disease (GERD). Aliment Pharmacol Ther, 27:846-51.

Ruigomez A, Garcia Rodriguez LA, Wallander MA, et al. 2004. Natural history of gastro-oesophageal reflux disease diagnosed in general practice. Aliment Pharmacol Ther, 20:751-60.

Schoffel L, Naumburger A, Gillessen A. 2004. Pantoprazole is significantly more effective in relieving GERD-associated sleep disturbances than omeprazole. Gut, 53(Suppl VI):A107.

Scholten S. 2007. Long-term management of gastroesophageal reflux disease with pantoprazole. Ther Clin Risk Manag, 3:231-43.

Sontag SJ, Sonnennberg A, Schnell TG, et al. 2006. The long-term natural history of gastroesophageal reflux disease. J Clin Gastroenterol, 40:398-404.

Stanghellini V. 2004. ReQuest - the challenge of quantifying both esophageal and extra-esophageal manifestations of GERD. Best Pract Res Clin Gastroenterol, 18(Suppl):27-30.

Stanghellini V, Armstrong D, Monnikes H, et al. 2004. Systematic review: do we need a new gastro-oesophageal reflux disease questionnaire? Aliment Pharmacol Ther, 19:463-79. 
Stanghellini V, Armstrong D, Monnikes H, et al. 2005. Determination of ReQuest-based symptom thresholds to define symptom relief in GERD clinical studies. Digestion, 71:145-51.

Stanghellini V. 2005. ReQuest: new dimensions in the assessment and management of GERD. Drugs, Today (Barc), 41(Suppl B):7-11.

Stanghelli V, Armstrong D, Mönnikes H, et al. 2005. Determination of ReQuest ${ }^{\mathrm{TM}}$-based symptom thresholds to define symptom relief in GERD clinical studies. Digestion, 71:145-51.

Stanghellini V, Armstrong D, Monnikes H, et al. 2006. Objective definition of symptom relief in clinical studies: determination of international GERD symptom thresholds based on ReQuest ${ }^{\mathrm{TM}}$. Gastroenterology, 130(Suppl 2):A-455.

Stephens RJ, Hopwood P, Girling DJ, et al. 1997. Randomized trails with quality of life endpoints: Are doctors' ratings of patients' physical symptoms interchangeable with patients' self-ratings? Qual Life Res, 6:225-36.

Thomson ABR, Barkun AN, Armstrong D, et al. 2003. The prevalence of clinically significant endoscopic findings in primary care patients with uninvestigated dyspepsia: The Canadian Adult Dyspepsia Empiric Treatment - Prompt Endoscopy (CADET-PE) Study. Aliment Pharmacol Ther, 17:481-91.
Thomson A, Peter S. ReQuest is a powerful instrument to differentiate treatment response [abstract]. Can J Gastroenterol, 21(Suppl A):118A (Abstr 157)

Vakil N, van Zanten SV, Kahrilas P, et al. 2006. The Montreal classification and definition of gastroesophageal reflux disease: a global evidencedbased consensus. Am J Gastroenterol, 101:1900-20.

Van Rensburg C, Bardhan K, Tulassay Z, et al. 2005. Pantoprazole $40 \mathrm{mg}$ is comparable to esomeprazole $40 \mathrm{mg}$ for first and sustained symptom relief in patients with erosive gastroesophageal reflux disease (GERD). Gastroenterology, 128(Suppl 2):A-530.

Wilklund I, Bardhan KD, Muller-Lissner S, et al. 1998. Quality of life during acute and intermittent treatment of gastro-oesophageal reflux disease with omeprazole compared with ranitidine. Results from a multicentre clinical trial. The European Study Group. Ital J Gastroenterol Hepatol, 30:19-27.

Wiklund I. 2001. Quality of life in patients with gastroesophageal reflux disease. Am J Gastroenterol, 96(Suppl 8):S46-53.

Winters C Jr, Spurling TJ, Chobanian SJ, et al. 1987. Barret's esophagus: a prevalent, occult complication of gastroesophageal reflux disease. Gastroenterology, 92:118-24. 